\title{
Glucocorticoids regulate the proliferation of $T$ cells via miRNA-155 in septic shock
}

\author{
YING CHEN, GUANG WANG, ZHONGMIN LIU, SHIJI WANG and YUSHAN WANG \\ Intensive Care Unit, The First Hospital of Jilin University, Changchun, Jilin 130021, P.R. China
}

Received January 5, 2014; Accepted January 29, 2016

DOI: 10.3892/etm.2016.3825

\begin{abstract}
Although previous studies have evaluated the roles of glucocorticoids and lymphocytes in septic shock, the precise mechanism remains unclear. The present study focused on investigating the influence of glucocorticoids on micro (mi)RNA-155 expression levels and the proliferation of $\mathrm{T}$ lymphocytes in septic shock. T cells were harvested from in the peripheral blood of patients with septic shock and healthy volunteers and were cultured in vitro. miRNA-155 levels and cell proliferation rates were subsequently analyzed. The proliferation of T cells from patients with septic shock was observed to be significantly lower as compared with that of T cells from healthy volunteers $(\mathrm{P}<0.05)$. Furthermore, miRNA-155 levels were significantly higher in the $\mathrm{T}$ cells from patients with septic shock, as compared with those from healthy volunteers $(\mathrm{P}<0.05)$. Notably, stimulation with dexamethasone increased the proliferation of $\mathrm{T}$ lymphocytes from patients with septic shock in a concentration-dependent manner, and markedly reduced miRNA-155 levels. Furthermore, transfection with an anti-miRNA-155 oligodoxynucleotide significantly increased the proliferation of $\mathrm{T}$ lymphocytes from patients with septic shock. In conclusion, the results of the present study indicate that glucocorticoids may regulate T-lymphocyte proliferation via the miRNA-155 pathway during septic shock. Therefore, miRNA-155 may be a potential therapeutic target in the treatment of septic shock.
\end{abstract}

\section{Introduction}

Sepsis in defined as a systemic inflammatory response to infection (1). The importance of immune function disorder in sepsis and septic shock has previously been demonstrated (2), and previous studies have demonstrated that $\mathrm{T}$ cells are pivotal in the pathogenesis of septic complications via suppression of the adaptive immune response (2-4). The role of $\mathrm{T}$ cells

Correspondence to: Professor Yushan Wang, Intensive Care Unit, The First Hospital of Jilin University, 71 Xinmin Street, Changchun, Jilin 130021, P.R. China

E-mail: wangyushanjilin@163.com

Key words: septic shock, miRNA-155, lymphocyte, glucocorticoids in the immune response of sepsis is well documented $(3,4)$, and it has previously been demonstrated that septic patients exhibit markedly decreased numbers of total T cells and CD4 ${ }^{+}$ T lymphocytes in their peripheral blood (5). Furthermore, previous studies have demonstrated that the persistent lymphopenia correlates with early and late mortality in sepsis or patients with septic shock (6-8). It has also been demonstrated that the early apoptosis of circulating lymphocytes in septic shock is associated with poor outcomes (7). Therefore, lymphopenia may serve as a biomarker for sepsis-induced immunosuppression and the prevention of lymphopenia may be a potential therapeutic strategy for the treatment of sepsis (8).

Glucocorticoids have anti-inflammatory, anti-allergic and anti-shock properties; therefore, they have been widely used to treat inflammatory and autoimmune diseases, including severe sepsis and septic shock (9). Previous studies have demonstrated that glucocorticoids prevent the release of proinflammatory cytokines via the regulation of lymphocyte function $(9,10)$; therefore, glucocorticoids may significantly improve lymphopenia in septic shock. However, the duration of treatment could differentially affect the patient response to treatment and the mechanisms underlying the role of glucocorticoids on lymphopenia in septic shock remain unclear.

Various studies have investigated the role of glucocorticoids in micro (mi)RNA regulation and have demonstrated that glucocorticoids may affect T-cell function or the apoptosis/proliferation of lymphocytes via miRNA regulation $(11,12)$. As a class of small non-coding RNA molecules, miRNA has been shown to have a critical role in cell proliferation/differentiation, apoptosis, innate immune responses and inflammation, including the regulation of lymphocyte function and sepsis $(13,14)$. Increasing evidence has indicated that miRNA-155 is a critical regulator of inflammation and immune function $(15,16)$. Previous studies have demonstrated that miRNA-155 has an important role in the regulation of various inflammatory and immunological diseases, including Graves' ophthalmopathy, allergic asthma, atherogenesis, multiple sclerosis and organ transplantation (17-21). Moreover, miRNA-155 has been associated with the regulation of immunity and inflammation in infectious diseases, including sepsis (21-23). This is supported by a previous study which demonstrated that glucocorticoids are capable of regulating miRNA-155 expression levels in the livers of septic mice (23). Although previous studies have elucidated that miRNA-155 has a critical role in 
the proliferation of $\mathrm{T}$ cells $(24,25)$, whether glucocorticoids regulate T-cell proliferation or function via miRNA-155 in patients with septic shock remains unclear.

The present study focused on the role of glucocorticoids in the regulation of miRNA-155 and T-cell proliferation in patients with septic shock.

\section{Materials and methods}

Patients. Adult patients were recruited from the Intensive Care Unit at the First Hospital of Jilin University (Jilin, China) between October 2012 and May 2014. Ethical approval was obtained from the Medical Ethics Committee of the First Hospital of Jilin University and informed consent was obtained from either the patients or the patients' families. Septic shock was diagnosed based on criteria outlined in the International Guidelines for Management of Severe Sepsis and Septic Shock: 2012 (26). The diagnosis of sepsis was made on the basis of an identifiable or suspected infection site and evidence of systemic inflammatory response syndrome manifested by at least two of the following criteria: i) Body temperature, $>38$ or $<36^{\circ} \mathrm{C}$; ii) respiratory rate, $>20$ breaths $/ \mathrm{min}$; iii) heart rate, $>90$ beats/min; iv) white blood cell count, $>12,000 / \mathrm{mm}^{3}$ or $<4,000 / \mathrm{mm}^{3}$. Septic shock was defined as sepsis-induced hypotension persisting despite adequate fluid resuscitation. Hypotension was defined as systolic blood pressure (SBP) $<90 \mathrm{mmHg}$, mean arterial pressure $<70 \mathrm{mmHg}$ or a SBP reduction of $>40 \mathrm{mmHg}$ or standard deviation below normal for the patient's age (26).

A total of 21 patients undergoing septic shock were enrolled in the septic shock group, and 25 healthy volunteers were included in the control group. Exclusion criteria included: i) Patients without informed consent; ii) patients $<18$ years old; iii) patients undergoing continuous renal replacement therapy prior to sampling; iv) patients receiving immunosuppressive therapy; and v) patients infected with viruses, including Mycobacterium tuberculosis. Blood samples collected by venous puncture were stored in BD Vacutainer tubes supplemented with lithium heparin (BD Biosciences, New Jersey, NY, USA) prior to steroid therapy. Blood samples from patients were collected within $24 \mathrm{~h}$ after the onset of septic shock. Demographic characteristics were also collected, and are shown in Table I.

Isolation of $T$ cells. Total $\mathrm{T}$ cells were isolated from peripheral blood samples by negative selection using a Rosette Sep kit (15022; Stem Cell Technologies, Vancouver, CA, USA). $\mathrm{T}$ cells were purified using the MACS Pan T Cell Isolation kit II (130-092-881; Miltenyi Biotec, Auburn, CA, USA), according to the manufacturer's protocol. $\mathrm{CD}^{+} \mathrm{T}$ cell purity was $\geq 96 \%$, as determined by flow cytometry (Attune NxT, Thermo Fisher Scientific, Inc., Waltham, MA, USA). Cells were cultured in RPMI-1640 medium (Thermo Fisher Scientific, Inc.) supplemented with $10 \%$ fetal bovine serum (Santa Cruz Biotechnology, Inc., Dallas, TX, USA) and antibiotics (100 U/ml penicillin and $0.1 \mathrm{mg} / \mathrm{ml}$ streptomycin).

Transfection with anti-miRNA-155 oligonucleotides (ODNs). Antisense ODNs against human miRNA-155 were used as the anti-miRNA-155 inhibitor (HmiR-AN0221-SN-10), and
Table I. Demographic characteristics of all subjects.

\begin{tabular}{lccc}
\hline Characteristics & $\begin{array}{c}\text { Control } \\
(\mathrm{n}=25)\end{array}$ & $\begin{array}{c}\text { Septic shock } \\
(\mathrm{n}=21)\end{array}$ & P-value \\
\hline Age, years & $65.2 \pm 13.4$ & $67.2 \pm 13.4$ & $>0.05$ \\
Gender, female/male & $16 / 9$ & $13 / 8$ & $>0.05$ \\
Leukocytes, $10^{9} / 1$ & $5.8 \pm 1.4$ & $14.6 \pm 5.5$ & $<0.001$ \\
Lymphocytes, $10^{9} / 1$ & $1.1 \pm 0.3$ & $0.3 \pm 0.1$ & $<0.001$ \\
Hs-CRP, mg/l & $2.3 \pm 0.7$ & $12.6 \pm 3.1$ & $<0.001$ \\
Infection site, $\mathrm{n}(\%)$ & & & \\
Lung & - & $9(42.9)$ & \\
Abdomen & - & $5(23.8)$ & \\
Blood & - & $3(14.3)$ & \\
Burn & - & $2(9.5)$ & \\
Others & - & $2(9.5)$ & \\
\hline
\end{tabular}

Data are presented as mean \pm standard deviation. Hs-CRP, high-sensitivity C-reactive protein.

negative control (NC) ODNs (CmiR-AN0001-SN) were also used as for comparison (both Genecopoeia Inc., Guangzhou, China). Cells at 40-60\% confluence were transfected. Individual ODNs were mixed with Lipofectamine 2000 (Thermo Fisher Scientific, Inc.) according to the manufacturer's protocol and were subsequently administered to the cells. The efficiency of ODN transfection was assessed by monitoring the uptake of siRNA labeled with 6-carboxyfluorescein. Furthermore, the transfection efficiency for each siRNA was $>90 \%$ and no significant difference existed between the two types of siRNA.

Reverse transcription-quantitative polymerase chain reaction $(R T-q P C R)$. Cells were seeded into 6-well plates at a concentration of $5 \times 10^{4}$ cells/well. Following treatment, total RNA was extracted from cells using TRIzol reagent (15596-018; Thermo Fisher Scientific, Inc.) according to the manufacturer's protocol. The RNA sample was treated with $10 \mathrm{U}$ of DNase I in a volume of $50 \mathrm{ml}(04716728001$; Roche Diagnostics, Basel, Switzerland) at $37^{\circ} \mathrm{C}$ for $20 \mathrm{~min}$. First-strand cDNA was synthesized using a reverse transcription kit (4368814; Thermo Fisher Scientific, Inc.). qPCR was performed in order to analyze miRNA-155 mRNA expression levels using a TaqMan Universal Master Mix II kit (4440040; Thermo Fisher Scientific, Inc.). $\beta$-actin was used as the reference gene. The abundance of miRNA-155 expression in each sample was determined relative to the abundance of the $\beta$-actin reference gene. The qPCR data were analyzed and expressed as the relative miRNA levels of the cycle threshold value, which was subsequently converted to the fold change with the $2^{-\triangle \Delta C T}$ method (27). The primer sequences of miR-155 were as follows: Sense, 5' TTAATGCTAATCGTGATAG,-3' and antisense 5'-ACCTGAGAGTAGACCAGA-3'.

Immunofluorescence staining. Cells were seeded into 24-well plates at a concentration of $1 \times 10^{4}$ cells/well. Following treatment, cells were fixed with $95 \%$ alcohol for $5 \mathrm{~min}$ and permeabilized with $0.5 \%$ Triton X-100 for $5 \mathrm{~min}$. Subsequently, 
A

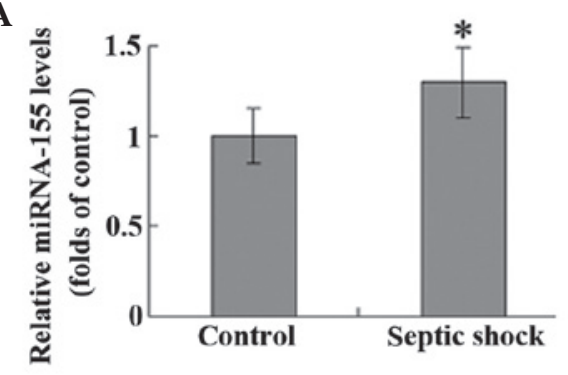

C

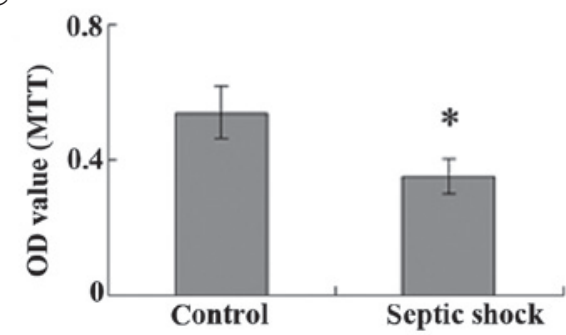

B

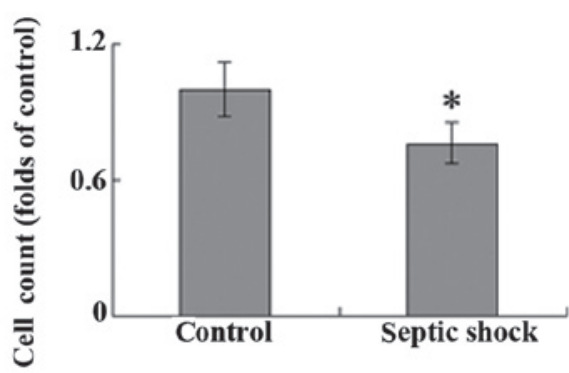

D

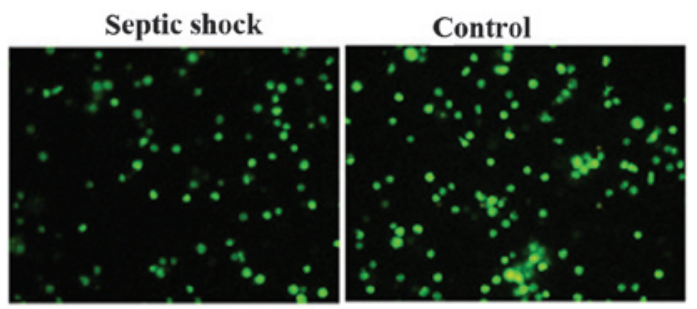

Figure 1. T cells were isolated from peripheral blood samples and stimulated with $10 \mu \mathrm{g} / \mathrm{ml}$ phytohemagglutinin. (A) miRNA-155 expression levels were detected using reverse transcription-quantitative polymerase chain reaction analysis. (B) Cell proliferation was evaluated using cell counting, (C) methyl thiazolyl tetrazolium (MTT) assay and (D) immunofluorescence staining of proliferating cell nuclear antigen. Magnification, $\mathrm{x} 100$. ${ }^{*} \mathrm{P}<0.05$ vs. the control $(\mathrm{n}=6)$. miRNA, microRNA; OD, optical density.

cells were incubated with $5 \%$ bovine serum albumin for $0.5 \mathrm{~h}$ to block non-specific binding. Then cells were incubated with antibodies against proliferating cell nuclear antigen (rabbit polyclonal antibody PCNA; 1:100; sc-25280, Santa Cruz Biotechnology, Inc.) for $2 \mathrm{~h}$ at room temperature. Following washing, cells were incubated with fluorescein isothiocyanate-conjugated anti-mouse immunoglobulin G secondary antibodies (sc-65561, Santa Cruz Biotechnology,Inc.,) prepared in phosphate-buffered saline (PBS) for $1 \mathrm{~h}$ at room temperature. Negative controls were conducted with PBS instead of the primary antibodies. Sections were examined using a fluorescence microscope (BX53, Olympus Corporation, Tokyo, Japan), and the results were expressed as the percentage of positive cells.

Cell proliferation. In order to investigate the rate of proliferation, $\mathrm{T}$ cells from patients and controls were stimulated with $10 \mu \mathrm{g} / \mathrm{ml}$ phytohemagglutinin (PHA; Sigma-Aldrich, St. Louis, MO, USA), and in a separate experiment, T cells from patients with septic shock were stimulated with 10, 50 or $100 \mathrm{nM}$ dexamethasone (DXM; D1756, Sigma-Aldrich). In both experiments, the duration of stimulation was $48 \mathrm{~h}$. Cell proliferation was evaluated using cell count and methyl thiazolyl tetrazolium (MTT) assays (Sigma-Aldrich).

For the cell count assay, cells were plated into 6 -well plates at a concentration of $5 \times 10^{4}$ cells/well. Following stimulation, cells were collected by trypsin (C0201, Beyotime Institute of Biotechnology, Haimen, China) digestion and total cell numbers were calculated using a hemocytometer (Countess Automated Cell Counter, Thermo Fisher Scientific, Inc.) following trypan blue (ST798, Beyotime Institute of Biotechnology) exclusion.

For the MTT assay, cells were seeded into 96-well plates at a concentration of $5 \times 10^{3}$ cells/well. Following treatment, $20 \mu \mathrm{l}$ MTT (ST316, Beyotime Institute of Biotechnology) was added to the wells and the plates were incubated for $4 \mathrm{~h}$.
The supernatant was subsequently removed and the plate was incubated with $150 \mu \mathrm{l} /$ well dimethyl sulfoxide (DMSO; Sigma-Aldrich) at room temperature for $10 \mathrm{~min}$ on a swing bed. Cells were quantified by spectrophotometry at $490 \mathrm{~nm}$ using an absorbance microplate reader (ELx800; BioTek Instruments, Inc., Winooski, VT, USA).

Statistical analysis. Data are expressed as the mean \pm standard deviation and were analyzed by t-test or one-way analysis of variance, followed by q-test using SPSS software, version 12.0 (SPSS, Inc., Chicago, IL, USA). For all tests, $\mathrm{P}<0.05$ was considered to indicate a statistically significant difference.

\section{Results}

Demographic characteristics of the study subjects. The demographic characteristics of subjects in the two groups are shown in Table I. No significant differences in gender or age were detected between the two groups. The levels of white blood cells (leukocytes) and serum high-sensitivity C-reactive protein were significantly higher in the septic shock group, as compared with the control group; whereas the lymphocyte count was significantly lower in the septic shock group, as compared with the control group. In the present study, the primary cause of septic shock was severe pneumonia $(n=9)$. Other causes included peritonitis $(n=5)$, injury $(n=2)$ and burn $(n=2)$.

miRNA-155 levels and T cell proliferation. miRNA-155 levels in $\mathrm{T}$ cells were significantly higher in the septic shock group, as compared with the control group $(\mathrm{P}<0.05$; Fig. 1A). A cells counting assay was used to evaluate T-cell proliferation, and stimulation with $10 \mathrm{mg} / \mathrm{ml}$ PHA was observed to promote the proliferation of $\mathrm{T}$ lymphocytes in patients with septic shock and the control group. Notably, the T cells harvested from 
A

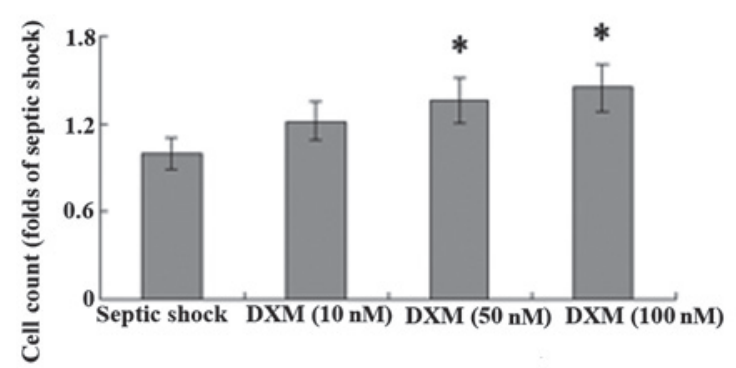

C

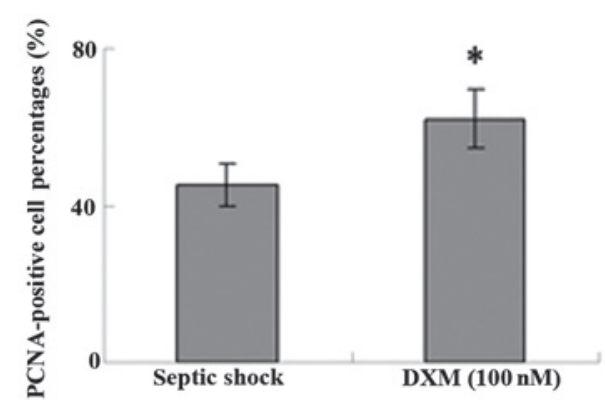

B

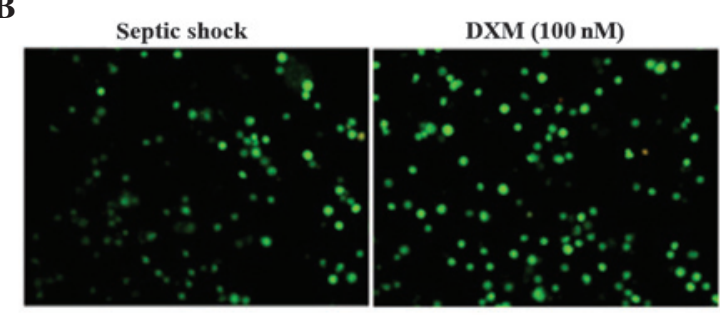

D

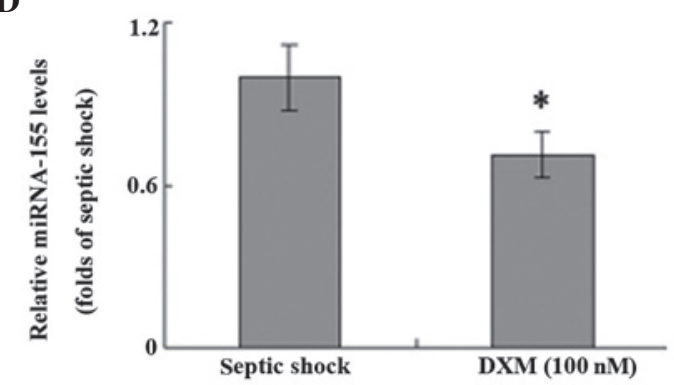

Figure 2. T cells were isolated from peripheral blood samples and stimulated with 10, 50 or $100 \mathrm{nM}$ DXM for $48 \mathrm{~h}$. Cell proliferation was evaluated using (A) cell count and (B and C) immunofluorescence staining of PCNA (magnification, x100). (D) miRNA-155 expression levels were detected using reverse transcription-quantitative polymerase chain reaction analysis. ${ }^{*} \mathrm{P}<0.05$ vs. septic shock (control; $\mathrm{n}=6$ ). $\mathrm{DXM}$ dexamethasone; PCNA, proliferating cell nuclear antigen; miRNA, microRNA.

the peripheral blood of patients with septic shock exhibited significantly weaker proliferative ability, as compared with the controls $(\mathrm{P}<0.05$; Fig. 1B). The results of MTT assay and PCNA staining were consistent with those demonstrated by the cells counts (Fig. 1C and D).

DXM regulates $T$-cell proliferation and miRNA-155 expression. In T cells harvested from patients with septic shock, treatment with DXM significantly increased the proliferation of cells in a concentration-dependent manner, as compared with that in the untreated controls (Fig. 2A; P<0.05). The results of PCNA staining were consistent with these results (Fig. 2B and C), which suggests that DXM treatment may have a role in the proliferation of $\mathrm{T}$ cells during septic shock. Furthermore, stimulation with DXM markedly inhibited the expression levels of miRNA-155 in the T cells of patients with septic shock (Fig. 2D).

miRNA-155 is associated with T-cell proliferation. In order to explore the role of miRNA-155 in the proliferation of T cells, miRNA-155 expression was knocked down using an ODN against human miRNA-155. The ODN anti-miRNA-155 inhibitor successfully significantly inhibited miRNA-155 mRNA expression levels in T cells (Fig. 3A). In a cell count assay, the anti-miRNA-155 inhibitor significantly increased the proliferation of $\mathrm{T}$ cells induced by $10 \mathrm{mg} / \mathrm{ml}$ PHA, as compared with that of untransfected cells $(\mathrm{P}<0.05$; Fig. $3 \mathrm{~B})$. Furthermore, transfection with this anti-miRNA-155 ODN resulted in a significant increase in the number of PCNA-positive cells in the T lymphocytes of patients with septic shock, as compared with the untransfected control (Fig. 3C; $\mathrm{P}<0.05$ ). These results suggest that miRNA-155 may be involved in the proliferation of $\mathrm{T}$ cells during septic shock.

\section{Discussion}

The results of the present study demonstrate that the miRNA-155 expression levels were increased in the $\mathrm{T}$ cells of patients with septic shock. Furthermore, DXM administration successfully inhibited miRNA-155 expression and promoted $\mathrm{T}$ cell proliferation, and a small-interfering RNA against miRNA-155 was demonstrated to significantly increase the proliferation of T cells during septic shock. These results suggest that miRNA-155 may be associated with the glucocorticoid-induced proliferation of $\mathrm{T}$ cells observed in patients with septic shock.

Lymphocytes have a critical role in the immune response of sepsis $(3,4)$ and it has previously been demonstrated that patients with septic shock exhibit significantly decreased levels of total and $\mathrm{CD}^{+}{ }^{+} \mathrm{T}$ lymphocytes in peripheral blood (5). Previous studies have demonstrated that apoptosis of T cells occurs during septic shock; however few have focused on the proliferative ability of $\mathrm{T}$ cells in patients with septic shock (5-7). The present study demonstrated that $\mathrm{T}$ cells from patients with septic shock exhibited weak proliferative ability under the stimulation of PHA. This suggests that PHA also participates in the persistent lymphopenia in septic shock; however, the importance and mechanism of the balance of proliferation/apoptosis of lymphocytes in patients with sepsis requires further clarification.

miRNAs have been demonstrated to have critical roles in cell proliferation, apoptosis, inflammation and the regulation of lymphocyte function (13-15). Previous studies have outlined the critical role of miRNA-155 in inflammatory and immune diseases (17-21), and the present study demonstrated the important role of miRNA-155 in septic shock. The results of the present study are consistent with previous studies in lipopolysaccharide (LPS)-induced septic mice. In 
A

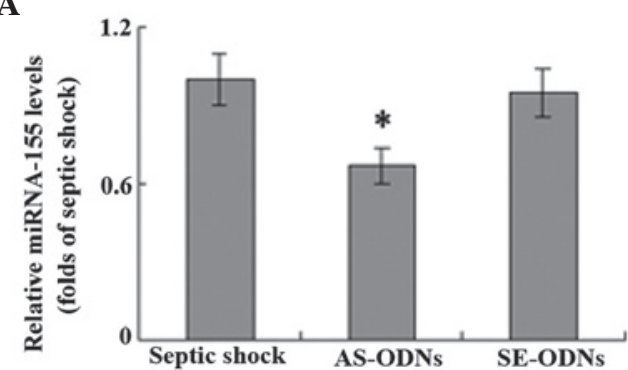

C

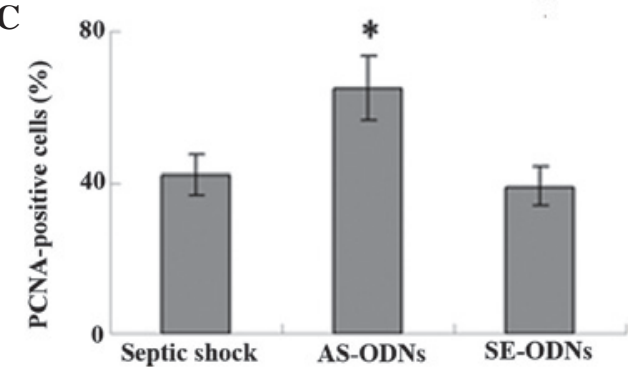

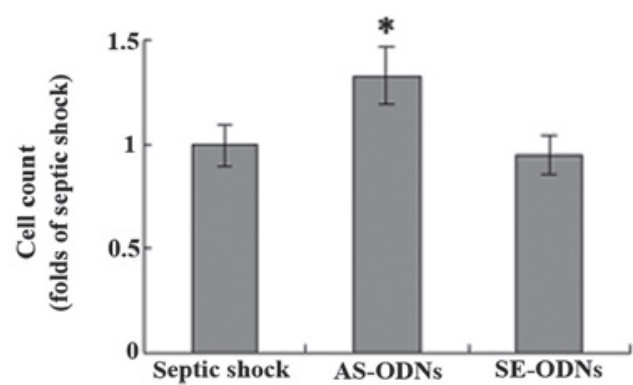

D

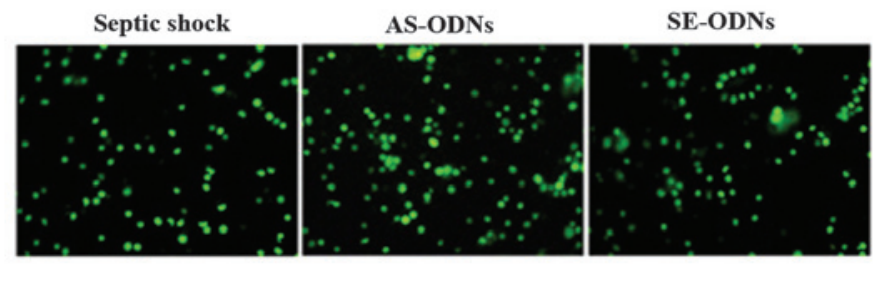

Figure 3. Total T cells were isolated from peripheral blood samples and stimulated with $10 \mathrm{ug} / \mathrm{ml}$ phytohemagglutinin. ODNs against human miRNA-155 were used as the anti-miRNA-155 inhibitor. (A) miRNA-155 expression levels were detected using reverse transcription-quantitative polymerase chain reaction analysis. Cells proliferation was evaluated using (B) cell count and (C and D) immunofluorescence staining of PCNA. Magnification, $\mathrm{x} 100$. * $\mathrm{P}<0.05 \mathrm{vs.}$ sseptic shock (control; n=6). AS-ODNs, antisense oligodeoxynucleotides against human miRNA-155; SE-ODNs, sense oligodeoxynucleotides complementary to human miRNA-155; PCNA, proliferating cell nuclear antigen.

a mice model of sepsis, Wang et al (23) demonstrated that LPS significantly increased miRNA-155 expression levels in liver tissues, in addition to several inflammatory factors. Another study demonstrated that LPS was capable of inducing miRNA-155 expression in the spleens of mice (21). These reports suggest that miRNA-155 has a critical role in sepsis and septic shock. Certain pathways, including glycogen synthase kinase- $3 \beta$ and arginase- 2 , have been found to be associated with the miRNA-155-mediated regulation of T-cell proliferation in cardiac allograft rejection in a murine transplantation model (14-25). Although other validated target genes of miRNA-155 have also been established $(28,29)$, their role in the proliferation of $\mathrm{T}$ lymphocytes during septic shock is yet to be elucidated.

Previous studies have demonstrated the critical role of glucocorticoid therapy in the treatment of septic shock; in particular, glucocorticoids may prevent the release of proinflammatory cytokines via the regulation of lymphocyte function $(9,10)$. The results of the present study suggest that glucocorticoids may promote the proliferation of $\mathrm{T}$ lymphocytes in patients with septic shock. It is well documented that glucocorticoids are capable of affecting T-cell function and lymphocyte apoptosis/proliferation via miRNAs, such as miR-98 and miR-17 (11,12). The present study indicated that miRNA-155 may be a target for glucocorticoids in $\mathrm{T}$ cells. This result is consistent with a previous study investigating a mouse model of sepsis, which demonstrated that treatment with DXM inhibited the expression of miRNA-155 to below baseline levels (23). These results indicate that miRNAs may be an important therapeutic target of glucocorticoids in the regulation of inflammatory and immunological diseases. Notably, it has been suggested that glucocorticoids may bind directly to the B-cell integration cluster gene to repress
miRNA-155 expression; however, this mechanism requires further investigation in patients with septic shock (30).

In conclusion, the present study demonstrates the key role of miRNA-155 in the proliferation of T cells in patients with septic shock. Therefore, although the precise molecular mechanism remains unclear, the regulation of miRNA-155 via glucocorticoids may be a novel therapeutic mechanism for the regulation of inflammation and immune response in patients with septic shock.

\section{References}

1. Annane D, Bellissant E and Cavaillon JM: Septic shock. Lancet 365: 63-78, 2005.

2. Chung CS, Watkins L, Funches A, Lomas-Neira J, Cioffi WG and Ayala A: Deficiency of gammadelta T lymphocytes contributes to mortality and immunosuppression in sepsis. Am J Physiol Regul Integr Comp Physiol 291: R1338-R1343, 2006.

3. Wisnoski N, Chung CS, Chen Y, Huang X and Ayala A: The contribution of $\mathrm{CD}^{+}{ }^{+} \mathrm{CD} 25^{+}$T-regulatory-cells to immune suppression in sepsis. Shock 27: 251-257, 2007.

4. Jiang LN, Yao YM and Sheng ZY: The role of regulatory T cells in the pathogenesis of sepsis and its clinical implication. J Interferon Cytokine Res 32: 341-349, 2012.

5. Inoue S, Suzuki-Utsunomiya K, Okada Y, Taira T, Iida Y, Miura N, Tsuji T, Yamagiwa T, Morita S, Chiba T, et al: Reduction of immunocompetent $\mathrm{T}$ cells followed by prolonged lymphopenia in severe sepsis in the elderly. Crit Care Med 41: 810-819, 2013.

6. Drewry AM, Samra N, Skrupky LP, Fuller BM, Compton SM and Hotchkiss RS: Persistent lymphopenia after diagnosis of sepsis predicts mortality. Shock 42: 383-391, 2014.

7. Le Tulzo Y, Pangault C, Gacouin A, Guilloux V, Tribut O, Amiot L, Tattevin P, Thomas R, Fauchet R and Drénou B: Early circulating lymphocytes apoptosis in septic shock is associated with poor outcome. Shock 18: 487-494, 2002.

8. Turrel F, Guignant C, Venet F, Lepape A and Monneret G: Innovative therapeutic strategies for restoring lymphocyte functions in septic patients. Inflamm Allergy Drug Targets 7: 181-186, 2008. 
9. Annane D, Bellissant E, Bollaert PE, Briegel J, Confalonieri M, De Gaudio R, Keh D, Kupfer Y, Oppert M and Meduri GU: Corticosteroids in the treatment of severe sepsis and septic shock in adults: A systematic review. JAMA 301: 2362-2375, 2009.

10. Keh D, Boehnke T, Weber-Cartens S, Schulz C, Ahlers O Bercker S, Volk HD, Doecke WD, Falke KJ and Gerlach H: Immunologic and hemodynamic effects of 'low-dose' hydrocortisone in septic shock: A double-blind, randomized, placebo-controlled, crossover study. Am J Respir Crit Care Med 167: 512-520, 2003.

11. Davis TE, Kis-Toth K, Szanto A and Tsokos GC: Glucocorticoids suppress $\mathrm{T}$ cell function by up-regulating microR NA-98. Arthritis Rheum 65: 1882-1890, 2013.

12. Smith LK, Shah RR and Cidlowski JA: Glucocorticoids modulate microRNA expression and processing during lymphocyte apoptosis. J Biol Chem 285: 36698-36708, 2010.

13. Rodriguez A, Vigorito E, Clare S, Warren MV, Couttet $P$, Soond DR, van Dongen S, Grocock RJ, Das PP, Miska EA, et al: Requirement of bic/microRNA-155 for normal immune function. Science 316: 608-611, 2007.

14. Wang HJ, Zhang PJ, Chen WJ, Jie D, Dan F, Jia YH and Xie LX Characterization and identification of novel serum microRNAs in sepsis patients with different outcomes. Shock 39: 480-487, 2013.

15. Yao R, Ma YL, Liang W, Li HH, Ma ZJ, Yu X and Liao YH: MicroRNA-155 modulates Treg and Th17 cells differentiation and Th17 cell function by targeting SOCS1. PLoS One 7: e46082, 2012.

16. Hu R, Huffaker TB, Kagele DA, Runtsch MC, Bake E, Chaudhuri AA, Round JL and O'Connell RM: MicroRNA-155 confers encephalogenic potential to Th17 cells by promoting effectorgene expression. J Immunol 190: 5972-5980, 2013.

17. Li K, Du Y, Jiang BL and He JF: Increased microRNA-155 and decreased microRNA-146a may promote ocular inflammation and proliferation in Graves' ophthalmopathy. Med Sci Monit 20: 639-643, 2014.

18. Malmhäll C, Alawieh S, Lu Y, Sjöstrand M, Bossios A, Eldh M and Rådinger M: MicroRNA-155 is essential for T(H)2-mediated allergen-induced eosinophilic inflammation in the lung. J Allergy Clin Immunol 133: 1429-1438, 2014.

19. Li J, Gong J, Li P, Li M, Liu Y, Liang S and Gong J: Knockdown of microRNA-155 in kupffer cells results in immunosuppressive effects and prolongs survival of mouse liver allografts. Transplantation 97: 626-635, 2014

20. Zhang J, Cheng Y, Cui W, Li M, Li B and Guo L: MicroRNA-155 modulates Th1 and Th17 cell differentiation and is associated with multiple sclerosis and experimental autoimmune encephalomyelitis. J Neuroimmunol 266: 56-63, 2014.
21. Tili E, Michaille JJ, Cimino A, Costinean S, Dumitru CD, Adair B, Fabbri M, Alder H, Liu CG, Calin GA and Croce CM: Modulation of miR-155 and miR-125b levels following lipopolysaccharide/TNF-alpha stimulation and their possible roles in regulating the response to endotoxin shock. J Immunol 179: 5082-5089, 2007.

22. Piccinini AM and Midwood KS: Endogenous control of immunity against infection: Tenascin-C regulates TLR4-mediated inflammation via microRNA-155. Cell Rep 2: 914-926, 2012.

23. Wang ZH, Liang YB, Tang H, Chen ZB, Li ZY, Hu XC and Ma ZF: Dexamethasone down-regulates the expression of microRNA-155 in the livers of septic mice. PLoS One 8: e80547, 2013.

24. Dunand-Sauthier I, Irla M, Carnesecchi S, Seguín-Estévez Q, Vejnar CE, Zdobnov EM, Santiago-Raber ML and Reith W: Repression of arginase-2 expression in dendritic cells by microRNA-155 is critical for promoting $\mathrm{T}$ cell proliferation. J Immunol 193: 1690-1700, 2014

25. Feng Z, Xia Y, Zhang M and Zheng J: MicroRNA-155 regulates $T$ cell proliferation through targeting GSK3 $\beta$ in cardiac allograft rejection in a murine transplantation model. Cell Immunol 281: 141-149, 2013

26. Dellinger RP, Levy MM, Rhodes A, Annane D, Gerlach H, Opal SM, Sevransky JE, Sprung CL, Douglas IS, Jaeschke R, et al: Surviving Sepsis Campaign Guidelines Committee including the Pediatric Subgroup. Surviving sepsis campaign: International guidelines for management of severe sepsis and septic shock. Crit Care Med 41: 580-637, 2012

27. Liu TE, Wang S, Zhang L, Guo L, Yu Z, Chen C and Zheng J: Growth hormone treatment of premature ovarian failure in a mouse model via stimulation of the Notch-1 signaling pathway. Exp Ther Med 12: 215-221, 2016.

28. Ceppi M, Pereira PM, Dunand-Sauthier I, Barras E, Reith W, Santos MA and Pierre P: MicroRNA-155 modulates the interleukin-1 signaling pathway in activated human monocyte-derived dendritic cells. Proc Natl Acad Sci USA 106: 2735-2740, 2009.

29. Lu F, Weidmer A, Liu CG, Volinia S, Croce CM and Lieberman PM: Epstein-Barr virus-induced miR-155 attenuates NF-kappaB signaling and stabilizes latent virus persistence. J Virol 82: 10436-10443, 2008.

30. Yin Q, Wang X, McBride J, Fewell C and Flemington E: B-cell receptor activation induces $\mathrm{BIC} / \mathrm{miR}-155$ expression through a conserved AP-1 element. J Biol Chem 283: 2654-2662, 2008. 